\title{
PI INDEX OF SOME BENZENOID GRAPHS
}

\section{ALI REZA ASHRAFI and AMIR LOGHMAN}

Department of Mathematics, Faculty of Science,

University of Kashan, Kashan, 87317-51167, Iran

\begin{abstract}
The Padmakar-Ivan (PI) index of a graph G is defined as $\mathrm{PI}(\mathrm{G})=\sum\left[\mathrm{n}_{\mathrm{eu}}(\mathrm{e} \mid \mathrm{G})+\mathrm{n}_{\mathrm{ev}}(\mathrm{e} \mid \mathrm{G})\right]$, where $\mathrm{n}_{\text {eu }}(\mathrm{e} \mid \mathrm{G})$ is the number of edges of $\mathrm{G}$ lying closer to u than to v, $n_{\text {ev }}(e \mid G)$ is the number of edges of $G$ lying closer to $v$ than to $u$ and summation goes over all edges of $G$. In this paper, we first compute the PI index of a class of pericondensed benzenoid graphs consisting of $\mathrm{n}$ rows, $\mathrm{n} \leq 3$, of hexagons of various lengths. Finally, we prove that for any connected graph $\mathrm{G}$ with exactly $\mathrm{m}$ edges, $\operatorname{PI}(\mathrm{G}) \leq \mathrm{m}(\mathrm{m}-1)$ with equality if and only if $\mathrm{G}$ is an acyclic graph or a cycle of odd length.
\end{abstract}

Keywords: Topological index, PI index, benzenoid graph, molecular graph.

\section{INTRODUCTION}

A topological index is a real number related to a molecular graph. It must be a structural invariant, i.e., it must not depend on the labeling or the pictorial representation of a graph. Many topological indices have been defined and several of them have found applications as means to model chemical, pharmaceutical and other properties of molecules ${ }^{1}$.

Here, we consider a new topological index, named the Padmakar-Ivan index, which is abbreviated as the PI index ${ }^{2-17}$. This newly proposed topological index, differ from the Wiener index ${ }^{18}$, the oldest topological index for acyclic (tree) molecules.

We now describe some notations which will be adhered to throughout. Benzenoid systems (graph representations of benzenoid hydrocarbons) are defined as finite connected plane graphs with no cut-vertices, in which all interior regions are mutually congruent regular hexagons. More details on this important class of molecular graphs can be found in the book of Gutman and Cyvin ${ }^{19}$ and in the references cited therein.

Let $\mathrm{G}$ be a simple molecular graph without directed or multiple edges and without loops, the vertex and edge-shapes of which are represented by $\mathrm{V}(\mathrm{G})$ and $E(G)$, respectively. The graph $G$ is said to be connected if for every pair of vertices $x$ and $y$ in $V(G)$ there exists a path between $x$ and $y$. In this paper we only consider connected graphs. If $e$ is an edge of $\mathrm{G}$, connecting the vertices $\mathrm{u}$ and $\mathrm{v}$ then we write $\mathrm{e}=\mathrm{uv}$. The number of vertices of $\mathrm{G}$ is denoted by $\mathrm{n}$. The distance between a pair of vertices $u$ and $w$ of $G$ is denoted by $d(u, w)$. We now define the PI index of a graph G. To do this, suppose that $\mathrm{e}=\mathrm{uv}$ and introduce the quantities $n_{\mathrm{eu}}(\mathrm{e} \mid \mathrm{G})$ and $\mathrm{n}_{\mathrm{ev}}(\mathrm{e} \mid \mathrm{G}) \cdot \mathrm{n}_{\mathrm{eu}}(\mathrm{e} \mid \mathrm{G})$ is the number of edges lying closer to vertex $u$ than to vertex $\mathrm{v}$, and $\mathrm{n}_{\mathrm{ev}} \mathrm{ev}_{\mathrm{ev}}(\mathrm{G})$ is the number of edges lying closer to vertex v than to vertex $u$. Then $\operatorname{PI}(G)=\sum\left[n_{e u}(e \mid G)+n_{e v}(e \mid G)\right]$, where the summation goes over all edges of $\mathrm{G}$. Edges equidistant from both ends of the edge $\mathrm{e}=\mathrm{uv}$ are not counted and the number of such edges is denoted by $\mathrm{N}(\mathrm{e})$. To clarify this, for every vertex $u$ and any edge $f=z w$ of graph $G$, we define $\mathrm{d}(\mathrm{f}, \mathrm{u})=\operatorname{Min}\{\mathrm{d}(\mathrm{u}, \mathrm{w}), \mathrm{d}(\mathrm{u}, \mathrm{z})\}$. Then $\mathrm{f}$ is equidistant from both ends of the edge $\mathrm{e}=\mathrm{uv}$ if $\mathrm{d}(\mathrm{f}, \mathrm{u})=\mathrm{d}(\mathrm{f}, \mathrm{v})$.

In a series of papers, Khadikar and coauthors ${ }^{2-17}$ defined and then computed the PI index of some chemical graphs. The present author ${ }^{20}$ computed the PI index of a zig-zag polyhex nanotube. In this paper we continue this study to prove an important result concerning the PI index and find an exact expression for the PI index of some other chemical graphs. Our notation is standard and mainly taken from the literature. ${ }^{21,22}$

\section{PI Index of some Benzenoid Graphs}

It is a well-known fact that the algebraic structure count of the linear phenylene with $\mathrm{h}$ six-membered rings is equal to $\mathrm{h}+1$. Gutman ${ }^{23}$ proved that the same expression is true if each four-membered ring in the phenylene is replaced by a linear array consisting of $\mathrm{k}, \mathrm{k}=4,7,10, \ldots$, four-membered rings. Here we find the PI index of this graph, which is denoted by T, Figure 1.

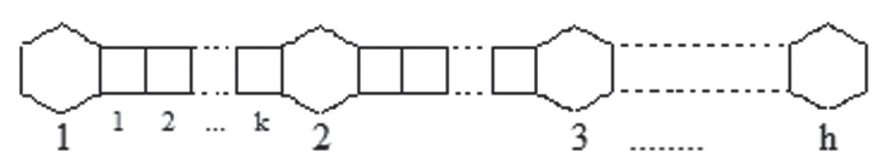

Figure 1. The graph of linear phenylenes.

Suppose $N(e)=|E|-\left(n_{\text {eu }}(e \mid G)+n_{\text {ev }}(e \mid G)\right)$, where e is an arbitrary edge of the graph of Figure 1. Then $\operatorname{PI}(\mathrm{T}) \stackrel{\text { ev }}{=}|\mathrm{E}|^{2}-\sum_{\text {efF }} \mathrm{N}(\mathrm{e})$. But $|\mathrm{E}(\mathrm{T})|=6 \mathrm{~h}+$ $(\mathrm{h}-1)(3 \mathrm{k}-1)$ and thus $\mathrm{PI}(\mathrm{T})=36 \mathrm{~h}^{2}+(\mathrm{h}-1)^{2}(3 \mathrm{k}-1)^{2}+12 \mathrm{~h}(\mathrm{~h}-1)(3 \mathrm{k}-1)-\sum_{\mathrm{e} \in \mathrm{E}}$ $\mathrm{N}(\mathrm{e})$. Therefore, to compute the PI index of T, it is enough to calculate N(e), for every e $\in \mathrm{E}$. To calculate $\mathrm{N}(\mathrm{e})$, we consider three cases such that e is vertical, horizontal or oblique. If $\mathrm{e}$ is horizontal or oblique then $\mathrm{N}(\mathrm{e})=2$ and for vertical edges we have $\mathrm{N}(\mathrm{e})=\mathrm{hk}+\mathrm{h}-\mathrm{k}+1$. Thus,

$\operatorname{PI}(\mathrm{T})=36 \mathrm{~h}^{2}+(\mathrm{h}-1)^{2}(3 \mathrm{k}-1)^{2}+12 \mathrm{~h}(\mathrm{~h}-1)(3 \mathrm{k}-1)$

$-2[6 \mathrm{~h}-2+2(\mathrm{~h}-1)(\mathrm{k}-1)]-(\mathrm{hk}+\mathrm{h}-\mathrm{k}+1)^{2}$.

If we put $\mathrm{k}=0$ in the last formula, then we obtain the PI index of polyacenes which has been computed before by Khadikar, Karmarkar and Varma $^{7}$. Therefore, we prove that:

Result 1: Let T be the chemical graph of the linear phenylene with $h$ sixmembered rings in which each four-membered ring in the phenylene is replaced by a linear array consisting of $k, k=4,7,10, \ldots$, four-membered rings. Then

$P I(T)=36 h^{2}+(h-1)^{2}(3 k-1)^{2}+12 h(h-1)(3 k-1)$ $-2[6 h-2+2(h-1)(k-1)]-(h k+h-k+1)^{2}$.

In particular, the PI index of polyacenes with $h$ hexagons is $24 h^{2}$.

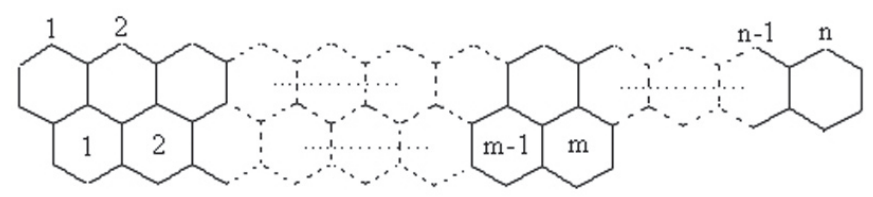

Figure 2. A pericondensed benzenoid graphs consisting of two rows of $\mathrm{n}$ and $\mathrm{m}$ hexagons, respectively, $\mathrm{m} \leq \mathrm{n}$.

Vuki $\square$ evi $\square$ and Trinajsti $\square^{24}$ obtained formulae for Wiener indices of a class of pericondensed benzenoid graphs consisting of three rows of hexagons of various lengths. They introduced the graph $\mathrm{G}(\mathrm{m}, \mathrm{n}, \mathrm{k})$ to be the pericondensed benzenoid graph given by Figure 3, in which $\mathrm{m}$ is a positive integer and $\mathrm{n}$, $\mathrm{k}$ are non-negative integers. In the case that $\mathrm{k}=0$, we denote this graph by $\mathrm{G}(\mathrm{m}, \mathrm{n})$, Figure 2. Here we continue this study to calculate the PI index of these chemical graphs.

We first consider a class of pericondensed benzenoid graphs consisting of two rows of hexagons of various lengths, Figure 2. Without loss of generality, we can assume that $\mathrm{n} \geq \mathrm{m}$.

It is easy to see that $G(m, n)$ has exactly $5 n+3 m+2$ edges. Suppose $A$ and 
$\mathrm{B}$ are the set of all vertical and oblique edges. To compute the size of A, we note that there are two rows of vertical edges. In the first row, $N(e)=n+1$ and in the second $\mathrm{N}(\mathrm{e})=\mathrm{m}+1$. Thus $\Sigma_{\mathrm{e} \in \mathrm{A}} \mathrm{N}(\mathrm{e})=(\mathrm{m}+1)^{2}+(\mathrm{n}+1)^{2}$. To compute $\Sigma_{\mathrm{e} \in \mathrm{B}} \mathrm{N}(\mathrm{e})$, we define:

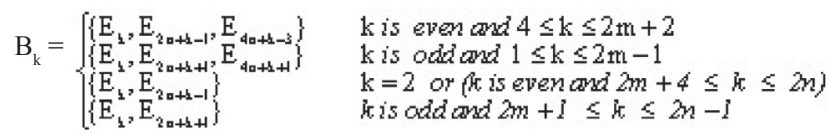

It is easy to see that the collection $\mathrm{P}=\left\{\mathrm{B}_{1}, \mathrm{~B}_{2}, \ldots, \mathrm{B}_{2,}\right\}$ is a partition for $\mathrm{B}$ and if we define $\mathrm{X}=\left(\mathrm{J}_{1 \leq \mathrm{sis} 2 \mathrm{n} \in \mathrm{Bi}=3} \mathrm{~B}_{\mathrm{i}}\right.$ and $\mathrm{Y}=\left(\bigcup_{1 \leq \mathrm{sis} 2 \mathrm{n} \& \mathrm{Bi} i=2} \mathrm{~B}_{\mathrm{i}}\right.$ then $\Sigma_{\mathrm{e} \in \mathrm{B}} \mathrm{N}(\mathrm{e})=\Sigma_{\mathrm{e} \in \mathrm{X}}$ $\mathrm{N}(\mathrm{e})+\Sigma_{\mathrm{e} \in \mathrm{Y}} \mathrm{N}(\mathrm{e})=\Sigma_{\mathrm{e} \in \mathrm{X}} 3+\Sigma_{\mathrm{e} \in \mathrm{Y}} 2=3|\mathrm{X}|+2|\mathrm{Y}|$. Since $|\mathrm{X}|=6 \mathrm{~m}$ and $|\mathrm{Y}|=4(\mathrm{n}-$ $\mathrm{m}), \Sigma_{\mathrm{e} \in \mathrm{B}} \mathrm{N}(\mathrm{e})=3|\mathrm{X}|+2|\mathrm{Y}|=10 \mathrm{~m}+8 \mathrm{n}$. Therefore, $\operatorname{PI}(\mathrm{G}(\mathrm{m}, \mathrm{n}))=8 \mathrm{~m}^{2}+24 \mathrm{n}^{2}+$ $30 \mathrm{mn}+10 \mathrm{n}+2$. Consequently, we prove the following result:

Result 2: If $n \geq m$ then $\operatorname{PI}(G(m, n))=8 m^{2}+24 n^{2}+30 m n+10 n+2$.

Finally, we consider a class of pericondensed benzenoid graphs consisting of three rows of hexagons of various lengths, Figure 3. To calculate the PI index of $\mathrm{G}(\mathrm{m}, \mathrm{n}, \mathrm{k})$, it is enough to consider four cases such that $\mathrm{m} \leq \mathrm{n}<\mathrm{k}$; $\mathrm{m}$ $<\mathrm{n}, \mathrm{k}$ and $\mathrm{n} \geq \mathrm{k} ; \mathrm{n}<\mathrm{m}, \mathrm{k}$; and $\mathrm{n}=\mathrm{m}=\mathrm{k}$, see Figure 3 . Two cases, where $\mathrm{k} \leq \mathrm{n}$ $<\mathrm{m} ; \mathrm{k}<\mathrm{n}, \mathrm{m}$ and $\mathrm{n} \geq \mathrm{m}$ are similar to the first two cases above. We have the following result:

Result 3. Let $G(m, n, k)$ be a benzenoid graph consisting of three rows of $m$, $n$ and $k$ hexagons, respectively. Then the PI index of $G(m, n, k)$ is as follows:

$\operatorname{PI}(\mathrm{G}(\mathrm{m}, \mathrm{n}, \mathrm{k}))= \begin{cases}8 \mathrm{~m}^{2}+8 \mathrm{n}^{2}+24 \mathrm{k}^{2}+8 m+12 \mathrm{n}+30 \mathrm{k}+18 \mathrm{mn}+30 \mathrm{mk}+30 \mathrm{nk}+16 & \mathrm{~m} \leq \mathrm{n}<\mathrm{k} \\ 8 \mathrm{~m}^{2}+48 \mathrm{n}^{2}+8 m+46 n-20 \mathrm{k}+42 m n-6 m k-14 n k+17 & \mathrm{~m}<\mathrm{n}, \mathrm{k} \& \mathrm{n} \geq \mathrm{k} \\ 24 \mathrm{~m}^{2}+24 \mathrm{k}^{2}+20 m-12 \mathrm{n}+20 \mathrm{k}+50 \mathrm{mk}+10 \mathrm{mn}+10 \mathrm{nk}+6 & \mathrm{n}<\mathrm{m}, \mathrm{k} \\ 61 \mathrm{~m}^{2}-6 \mathrm{~m}+7 & \mathrm{~m}=\mathrm{n}=\mathrm{k}\end{cases}$

Proof. Suppose $\mathrm{E}=\mathrm{E}(\mathrm{G}(\mathrm{m}, \mathrm{n}, \mathrm{k}))$ and $\mathrm{X}$ and $\mathrm{Y}$ are the set of all vertical and oblique edges, respectively. Choose e $\in$ X. To compute $\mathrm{N}(\mathrm{e})$, we consider three separate cases where e is an edge in the first, second or third row of $\mathrm{G}(\mathrm{m}, \mathrm{n}, \mathrm{k})$. In the first row, $\mathrm{N}(\mathrm{e})=\mathrm{m}+1$, in the second $\mathrm{N}(\mathrm{e})=\mathrm{n}+1$ and in the last $\mathrm{N}(\mathrm{e})=\mathrm{k}$ +1 , so that $\Sigma$ N $(\mathrm{e})=(\mathrm{m}+1)^{2}+(\mathrm{n}+1)^{2}+(\mathrm{k}+1)^{2}$. Obviousely, PI $(\mathrm{G}(\mathrm{m}, \mathrm{n}, \mathrm{k}))$ $=|E|^{2}-\sum_{e \in E} N(e)=|E|^{2}-\sum_{e \in X} N(e)-\sum_{e \in Y} N(e)$ and therefore to compute the $P I$ index of $G(m, n, k)$, it is enough to calculate the values $|E|$ and $\sum_{e \in Y} N(e)$. Set $\mathrm{A}=\{\mathrm{e} \in \mathrm{Y} \mid \mathrm{N}(\mathrm{e})=2\}, \mathrm{B}=\{\mathrm{e} \in \mathrm{Y} \mid \mathrm{N}(\mathrm{e})=3\}$ and $\mathrm{C}=\{\mathrm{e} \in \mathrm{Y} \mid \mathrm{N}(\mathrm{e})=4\}$. Our main proof will consider three cases:

Case 1. $m \leq n<k$. In this case according to Figure 3(a), we have:

$|\mathrm{A}|=2(2 \mathrm{k}-2 \mathrm{n})+2$,

$|\mathrm{B}|=3(2 \mathrm{n}-2 \mathrm{~m}+1)$,

$|\mathrm{C}|=4(2 \mathrm{~m}-1)$, and,

$|\mathrm{E}|=2(2 \mathrm{~m})+2(2 \mathrm{k})+(2 \mathrm{n}-2 \mathrm{~m}+1)+(\mathrm{m}+1)+(\mathrm{n}+1)+(\mathrm{k}+1)$

$=3 \mathrm{~m}+3 \mathrm{n}+5 \mathrm{k}+4$

Therefore $\sum_{\mathrm{e} \in \mathrm{Y}} \mathrm{N}(\mathrm{e})=\sum_{\mathrm{e} \in \mathrm{A}} 2+\sum_{\mathrm{e} \in \mathrm{B}} 3+\sum_{\mathrm{e} \in \mathrm{C}} 4=2|\mathrm{~A}|+3|\mathrm{~B}|+4|\mathrm{C}|=14 \mathrm{~m}$

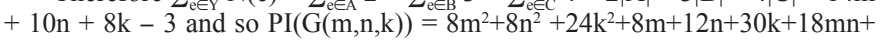
$30 \mathrm{mk}+30 \mathrm{nk}+16$.

Case 2. $m \leq n$ and $n \geq k$. In this case according to Figure 3(b), we have:

$|\mathrm{A}|=2(2 \mathrm{n}-2 \mathrm{k}+3)$,

$|\mathrm{B}|=3(2 \mathrm{k}-2 \mathrm{~m})$,

$|C|=4(2 \mathrm{~m}-1)$, and,

$\mathrm{E} \mid=2 \mathrm{~m}+2(2 \mathrm{n})+2 \mathrm{n}-2 \mathrm{k}+1+\mathrm{m}+1+\mathrm{n}+1+\mathrm{k}+1$

$=3 \mathrm{~m}+7 \mathrm{n}-\mathrm{k}+4$

Thus $\sum_{\mathrm{e} \in \mathrm{Y}} \mathrm{N}(\mathrm{e})=2|\mathrm{~A}|+3|\mathrm{~B}|+4|\mathrm{C}|=14 \mathrm{~m}+8 \mathrm{n}+10 \mathrm{k}-4$ and hence $\mathrm{PI}(\mathrm{G}(\mathrm{m}, \mathrm{n}, \mathrm{k}))=8 \mathrm{~m}^{2}+48 \mathrm{n}^{2}+8 \mathrm{~m}+46 \mathrm{n}-20 \mathrm{k}+42 \mathrm{mn}-6 \mathrm{mk}-14 \mathrm{nk}+17$.

Case 3. $n<m, k$. In this case, according to Figure 3(c), we have:

$|A|=2(2 k-4 n+2 m)$,

$|\mathrm{B}|=0$,

$|\mathrm{C}|=8 \mathrm{n}$, and,

$|E|=2(2 m)+2(2 k)+m+1+n+1+k+1=5 m+5 k+n+3$.
Therefore $\sum_{\mathrm{e} \in Y} \mathrm{~N}(\mathrm{e})=2|\mathrm{~A}|+3|\mathrm{~B}|+4|\mathrm{C}|=32 \mathrm{n}+4(2 \mathrm{k}+2 \mathrm{~m}-4 \mathrm{n})=16 \mathrm{n}+8 \mathrm{k}$ $+8 \mathrm{~m}$ and so $\mathrm{PI}(\mathrm{G}(\mathrm{m}, \mathrm{n}, \mathrm{k}))=24 \mathrm{~m}^{2}+24 \mathrm{k}^{2}+20 \mathrm{~m}-12 \mathrm{n}+20 \mathrm{k}+10 \mathrm{mn}+50 \mathrm{mk}$ $+10 \mathrm{nk}+6$.

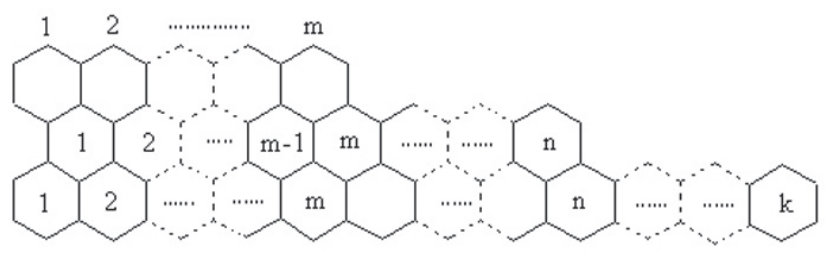

(a) m $\leq$ n $<\mathrm{k}$

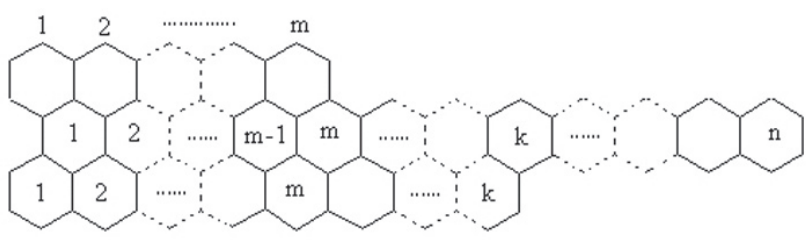

(b) m $<$ n, k and n $\geq \mathrm{k}$

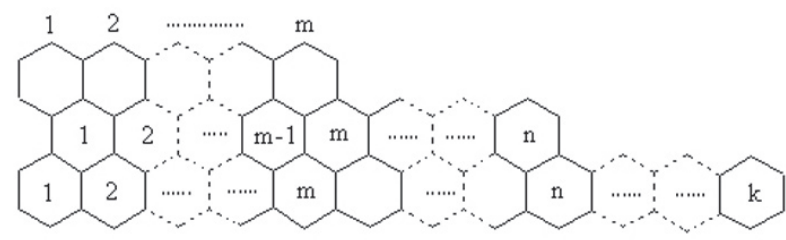

(c) n $\leq \mathrm{m}$ and $\mathrm{n} \leq \mathrm{k}$

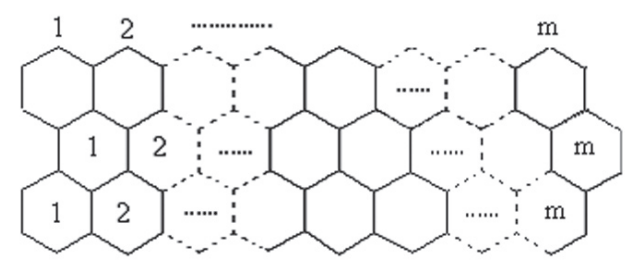

(d) $\mathrm{n}=\mathrm{m}=\mathrm{k}$

Figure 3. The pericondensed benzenoid graphs consisting of three rows of $\mathrm{n}, \mathrm{m}$ and $\mathrm{k}$ hexagons.

Case 4. $n=m=k$. In this case, according to Figure $3(\mathrm{~d}),|\mathrm{A}|=4,|\mathrm{~B}|=6,|\mathrm{C}|$ $=8(\mathrm{~m}-1)$, and $|\mathrm{E}|=8 \mathrm{~m}+2$. Therefore $\sum_{\mathrm{e} \in \mathrm{Y}} \mathrm{N}(\mathrm{e})=2|\mathrm{~A}|+3|\mathrm{~B}|+4|\mathrm{C}|=32 \mathrm{~m}-$ 6 and so $\operatorname{PI}(G(m, n, k))=61 m^{2}-6 m+7$. This completes the proof.

\section{An Upper Bound for the PI Index of a Graph}

The Wiener index $\mathrm{W}$ was the first topological index to be used in chemistry ${ }^{13}$. It was introduced in 1947 by Harold Wiener, as the path number for characterization of alkanes. In chemical language, the Wiener index is equal to the sum of all the shortest carbon-carbon bond paths in a molecule. In graphtheoretical language, the Wiener index is equal to the count of all the shortest distances in a graph.

Result 4: (Khadikar, Karmarkar and Agrawal, [5]) If $G$ is an acyclic graph (tree) containing $n$ vertices then $P I(G)=(n-1)(n-2)$. In particular, $P I=0$, for acyclic graphs when $n=1$ and 2 .

Since every acyclic graph with $n$ vertices has exactly $m=n-1$ edges, 
the previous result states that in every acyclic graph $\mathrm{G}$ with $\mathrm{m}$ edges $\mathrm{PI}(\mathrm{G})=$ $\mathrm{m}(\mathrm{m}-1)$. We now prove a weaker result about the relationship between the PI index and the number of edges in every connected graph. Before stating our result, we recall that the number of edges in a cycle $\mathrm{T}$ of a graph $\mathrm{G}$ is called the length of $\mathrm{T}$.

Result 5: Let $G$ be a connected graph with exactly $m$ edges. Then PI $(G)$ $\leq m(m-1)$ with equality if and only if $G$ is a cycle of odd length or an acyclic graph.

Proof. Suppose e $=u v$ is an edge of G. It is clear that $n_{e u}(e \mid G)+n_{e v}(e \mid G)+$ $\mathrm{N}(\mathrm{e})=\mathrm{m}$ and so $\mathrm{PI}(\mathrm{G})=\mathrm{m}^{2}-\sum_{\mathrm{e} \in \mathrm{F}} \mathrm{N}(\mathrm{e})$. But $\mathrm{N}(\mathrm{e}) \geq 1$ and hence $\sum_{\mathrm{e} \in \mathrm{F}} \mathrm{N}(\mathrm{e}) \geq$ $\sum_{\mathrm{e} \in \mathrm{E}} 1=\mathrm{m}$. Therefore, $\mathrm{PI}(\mathrm{G})=\mathrm{m}^{2}-\sum_{\mathrm{e} \in \mathrm{E}} \mathrm{N}(\mathrm{e}) \leq \mathrm{m}^{2}-\mathrm{m}=\mathrm{m}(\mathrm{m}-1)$. We now assume that $\mathrm{PI}(\mathrm{G})=\mathrm{m}(\mathrm{m}-1)$. From Result 1 , it is enough to consider nonacyclic graphs. Thus $\mathrm{G}$ has a cycle $\mathrm{C}$ of minimum length $\mathrm{k}, \mathrm{k} \geq 3$. If there exists an edge e for which $\mathrm{N}(\mathrm{e})>1$ then $\sum_{\mathrm{e} \in \mathrm{E}} \mathrm{N}(\mathrm{e})>\mathrm{m}$ and so $\mathrm{PI}(\mathrm{G})<\mathrm{m}(\mathrm{m}-1)$, which is a contradiction. Hence for every edge e, $N(e)=1$. Suppose that $C=x_{1} x_{2} x_{2} x_{3}$, $\ldots, \mathrm{x}_{\mathrm{k}-1} \mathrm{x}_{\mathrm{k}}, \mathrm{x}_{\mathrm{k}} \mathrm{x}_{1}$. We now consider two cases that $\mathrm{k}$ is either odd or even.

Case 1. $k$ is even. Suppose that $\mathrm{f}=\mathrm{x}_{1} \mathrm{x}_{2}$ is an edge of $\mathrm{C}$. Consider the edge $\mathrm{g}$ $=\mathrm{x}_{\mathrm{k} / 2+1} \mathrm{x}_{\mathrm{k} / 2+2}$. Since $\mathrm{C}$ has minimum length, $\mathrm{d}(\mathrm{g}, \mathrm{x} 1)=\mathrm{d}(\mathrm{g}, \mathrm{x} 2)=\mathrm{k} / 2-1$. Thus, $\mathrm{g}$ is equidistant from both end of the edge $\mathrm{f}$ and hence $\mathrm{N}(\mathrm{f}) \geq 2$, a contradiction.

Case 2. $k$ is odd. Suppose that $\mathrm{f}=\mathrm{x}_{1} \mathrm{x}_{2}$ and $\mathrm{v}=\mathrm{x}_{2+(\mathrm{k}-1) / 2}$. If $\operatorname{deg}(\mathrm{v})>2$ then we can choose an edge $\mathrm{g}=\mathrm{uv}$, in which $\mathrm{u}$ is distinct from $\mathrm{x}_{\mathrm{i}}$ 's. Hence $\mathrm{d}\left(\mathrm{g}, \mathrm{x}_{1}\right)=$ $\mathrm{d}\left(\mathrm{g}, \mathrm{x}_{2}\right)=(\mathrm{k}-1) / 2$, which is impossible. Therefore $\operatorname{deg}\left(\mathrm{x}_{1}\right)=2$. Using a similar argument, we can see that for any $\mathrm{i}, 2 \leq \mathrm{i} \leq \mathrm{k}, \operatorname{deg}\left(\mathrm{x}_{\mathrm{i}}\right)=2$. But $\mathrm{G}$ is connected, so $\mathrm{G}=\mathrm{C}$, as desired.

Conversely, if $\mathrm{G}$ is a tree, then, according to Result $1, \mathrm{PI}(\mathrm{G})=\mathrm{m}(\mathrm{m}-1)$, in which $\mathrm{m}=|\mathrm{E}(\mathrm{G})|$. Also, in every cycle $\mathrm{G}$ with odd length $\mathrm{k}$, we have $\mathrm{PI}(\mathrm{G})=$ $\mathrm{m}(\mathrm{m}-1)$, which completes the proof.

It is easy to see that $\mathrm{PI}\left(\mathrm{K}_{\mathrm{n}}\right)=\mathrm{n}(\mathrm{n}-1)(\mathrm{n}-2)$, in which $\mathrm{K}_{\mathrm{n}}$ is the complete graph on $\mathrm{n}$ vertices. We end this paper with the following question:

Question: Under what condition is the PI index of a graph with $n$ vertices $n(n-1)(n-2)$ ?

\section{ACKNOWLEDGMENT}

This research was in part supported by a grant from the Center of Excellence of Algebraic Methods and Applications of Isfahan University of Technology. We are very grateful to professor P.V. Khadikar for pointing out some good references on the subject of PI index of a molecular graphs.

\section{REFERENCES}

1. Todeschini, R.; Consonni, V. Handbook of Molecular Descriptors; Wiley: Weinheim, 2000.

2. Khadikar, P.V. Nat Acad Sci Lett-India, 2004, 23, 113.

3. Khadikar, P.V.; Karmarkar, S.; Agrawal, V.K. Nat Acad Sci Lett-India 2000, 23, 124.

4. Khadikar, P.V.; Karmarkar, S.; Agrawal, V.K. Nat Acad Sci Lett-India 2000, 23, 165.

5. Khadikar, P.V.; Karmarkar S.; Agrawal, V.K. J Chem Inf Comput Sci 2001, 41, 934.

6. Khadikar, P.V.; Kale, P.P.; Deshpande, N.V.; Karmarkar S.; Agrawal, V.K. J Math Chem 2001, 29, 143

7. Khadikar, P.V.; Karmarkar S.; Varma, R.G. Acta Chim Slov 2002, 49, 755.

8. Khadikar, P.V.; Agrawal, V.K.; Karmarkar, S. Bioorg Med Chem 2002, $10,3499$.

9. Khadikar, P.V.; Karmarkar, S.; Singh, S.; Shrivastava, A. Bioorg Med Chem 2002, 10,3163.

10. Khadikar, P.V.; Phadnis, A.; Shrivastava, A. Bioorg Med Chem 2002, 10, 1181.

11. Khadikar, P.V.; Mandloi, D.; Bajaj, A.V.; Joshi, S. Bioorg Med Chem Lett 2003, 13, 419.

12. Khadikar, P.V.; Joshi, S.; Bajaj, A.V.; Mandloi, D. Bioorg Med Chem Lett 2004, 14, 1187.

13. Jaiswal, M.; Khadikar, P.V.; Supuran, C.T. Bioorg Med Chem 2004, 12, 2477.

14. Jaiswal M.; Khadikar, P.V.; Bioorg Med Chem 2004, 12, 1731.

15. Khadikar, P.V.; Mandloi D.; Bajaj, A.V. Oxid Commun 2004, 27, 23.

16. Khadikar, P.V.; Mandloi D.; Bajaj, A.V. Oxid Commun 2004, 27, 29.

17. Khadikar, P.V.; Agrawal, V.K.; Karmarkar, S. Oxid Commun 2004, 27, 17.

18. H. Wiener, J Am Chem Soc 1947, 69, 17.

19. Gutman, I.; Cyvin, S.J. Introduction to the Theory of Benzenoid Hydrocarbons; Springer-Verlag: Berlin, 1989.

20. Ashrafi, A.R.; Loghman, A. MATCH Commun Math Comput Chem 2006, 55,447 .

21. Cameron, P.J. Combinatorics: Topics, Techniques, Algorithms; Cambridge University Press: Cambridge, 1994.

22. Trinajstić, N. Chemical Graph Theory, CRC Press: Boca Raton, FL. 1992.

23. Vukičević, D.; Trinajstić, N. Bulletin of Chemist and Technologists of Macedonia 2004, 23, 113.

24. Gutman, I. J. Serb. Chem. Soc. 2003, 68, 391 . 